\title{
The prevalence of oppositional defiant disorder and related factors among students of primary schools in Sanandaj in 2014
}

\author{
Fayegh Yousefi $^{1}$, Sara Shahvesi ${ }^{2}$, Mohammad Shahvesi $^{2}$, Karo Servatyari $^{3}$ \\ 1-Associate Professor, Department of Psychology, Social Determinants of Health Research Center, Kurdistan \\ University of Medical Sciences, Sanandaj, Iran. \\ 2- General Practice, Student Research Committee, Kurdistan University of Medical Sciences, Sanandaj, Iran. \\ 3- Medical Student, Student Research Committee, Kurdistan University of Medical Sciences, Sanandaj, Iran. \\ Corresponding Author: Karo Servatyari $\quad$ E-mail: k.servatyari@muk.ac.ir
}

Received: 14/11/2019

Accepted: 22/02/2020

\begin{abstract}
Introduction: Oppositional Defiant Disorder (ODD) includes children who have negatively oriented, aggressive behavior, capricious and disobedient to authority in during a minimum period of 6 months. Due to the difficulty in changing behavioral patterns in adulthood, early diagnosis can prevent potential threats in the future.
\end{abstract}

Aim: Determine the prevalence of oppositional defiant disorder and related factors among students in primary school in Sanandaj city in 2014.

Method: This study was a cross-sectional study. The study population consisted of primary school students living in the city of Sanandaj in 2014. The sample size based on Morgan's table was 377 people who were selected by stratified random sampling. Students who had other psychiatric disorders or had not informed consent were excluded from the study. Instruments of this study were Standard Child Symptom Inventory questionnaire. The questionnaire has two parent and teacher checklist. For data analysis, T-test and Pearson correlation coefficient were used.

Results: Among 377students, 62.6\% (236 students) were male and 37.4\% (141 students) were female. Results showed that the prevalence of ODD in respondents was $9.2 \%$. In this study, there was no statistically significant relationship between ODD with age $(\mathrm{P}=0.8)$. There was no significant relationship ( $\mathrm{p} \geq 0.14)$ between ODD and father's education, whereas, there was a significant relationship $(\mathrm{p} \leq 0.0001)$ between mothers' education and ODD $(\mathrm{p} \leq 0.001)$.

Conclusion: Due to the $2.9 \%$ prevalence of this disorder and its importance in shaping the personality and behavior of children, planning to reduce the risks posed by it, as well as the factors creating it, is necessary.

Keywords: Oppositional defiant disorder (ODD), Prevalence, Elementary students, Sanandaj

How to cite this article : Yousefi F, Shahvesi S, Shahvesi M, Servatyari K. The prevalence of oppositional defiant disorder and related factors among students of primary schools in Sanandaj in 2014. Shenakht Journal of Psychology and Psychiatry. 2020; 7 (1): 117-125 . URL: http://shenakht.muk.ac.ir/article-1-691-fa.pdf

Copyright $\odot 2018$ the Author (s). Published by Kurdistan University of Medical Sciences. This is an open access article distributed under the terms of the Creative Commons Attribution-Non Commercial License 4.0 (CCBY-NC), where it is permissible to download, share, remix, transform, and buildup the work provided it is properly cited. The work cannot be used commercially without permission from the journal. 


\title{
بررسى شيوع نافرمانى مقابلهاى در بين دانش آموزان ابتدائى شهرستان سندج

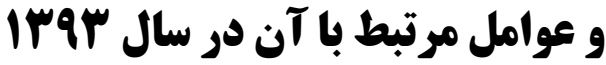

\author{
فايق يوسفى'، سارا شاهويسى'، محمد شاهويسى'، كارو ثروت يارى

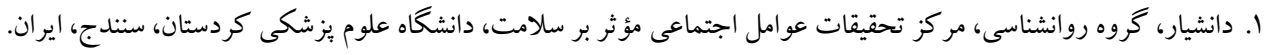

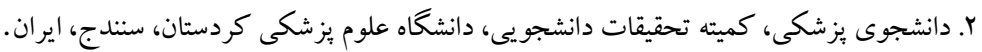

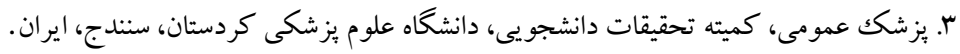 \\ k.servatyari@muk.ac.ir ايميل \\ مولف مسئول: كارو ثروت يارى
}

مقدمه: اختلال نافرمانى مقابلهاى شامل كود كانى است كه در طول يكك دوره حداقل 9 ماهه، منفى گرا، داراى رفتار خصمانه،

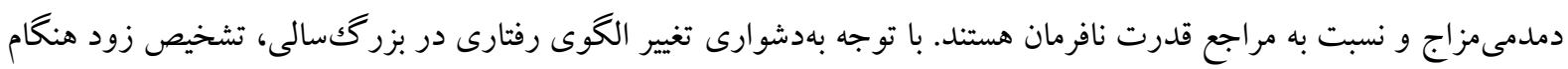

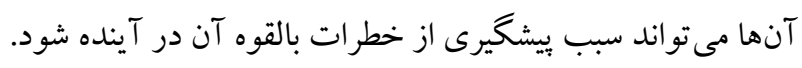

هدف: تعيين شيوع اختلال نافرمانى مقابلهاى و عوامل مرتبط با آن در بين دانشآموزان ابتدايى شهرستان سنندج در سال سوسا

روش: مطالعه حاضر، يك مطالعه مقطعى بوده و جامعه موردمطالعه شامل دانش آموزان مقطع ابتدايى شهرستان سنندج در سال

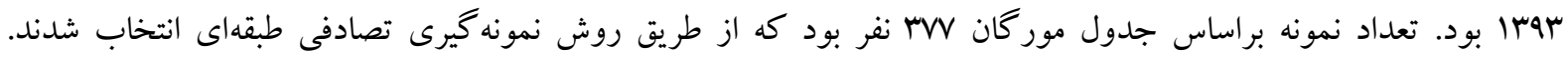

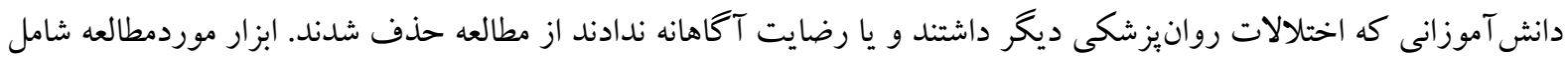

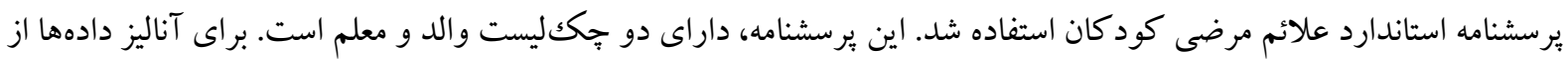
T-test

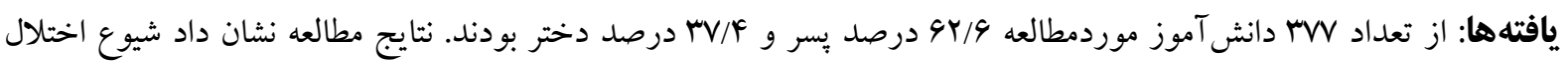

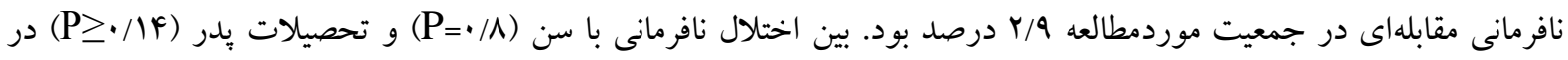

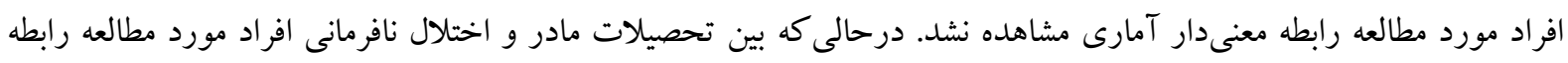

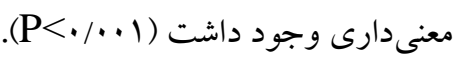

نتيجه كيرى: با توجه به شيوع Y/9 درصدى اين اختلال و اهميت آن در شكل گيرى شخصيت و رفتار كود كان، برنامهريزى در

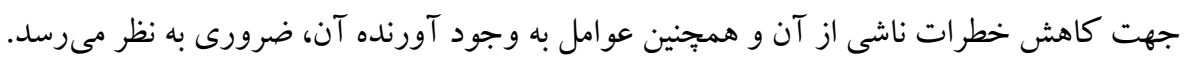
كليدوازه ها: اختلال نافرمانى مقابلهاى، شيوع، دانش آموزان ابتدايى، سنندج 
شيوع نافرمانى مقابلهاى در جمعيتهاى مختلف

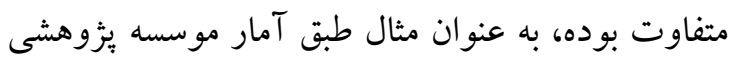
آمريكا در سال شيوع ميانگين س/ب درصد بوده (موسسه

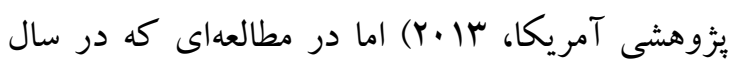
IMAF مقابلهاى را در كودكان دبستانى r/9 درصد برآ بآورد

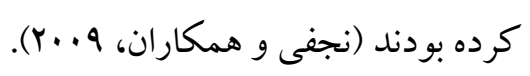

از علل به وجود آورنده آن مى توان به جنسيت و سابقه

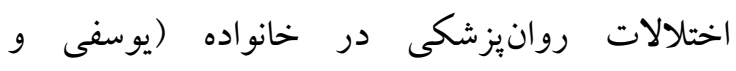
همكاران"' (ميكو لاجوسكى، تيلور، ياكونو "، (Y.IV)، فاكتورهاى

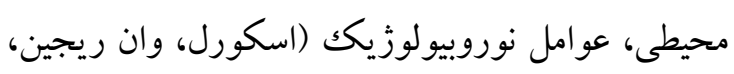

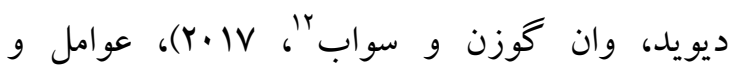
عوارض دوران باردارى و تولد (مصرف سيگار در مادر

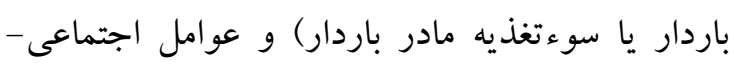

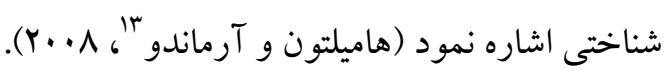
با توجه به مطالعه ثروت يارى و همكاران، اختلالات

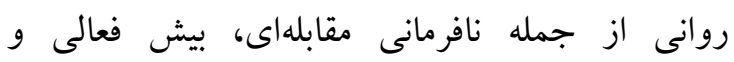
افسردگى مىتواند تأثير مخربى بر كيفيت خواب درائ در دانش آموزان داشته باشد (ثروت يارى و همكاران"

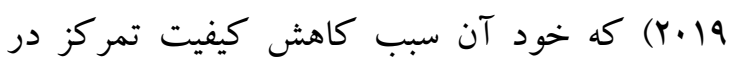
كلاس درس و در نهايت افت تحصيلى در كود كان را

$$
\text { شامل مى شود (ثروت يارى و همكاران، 19 19). }
$$
تحقيقات اخير نشان مىدهد كه نشانهات لنهاى اختلال نافرمانى مقابلهاى در بزرگك سالى هم ديده خو اهد شد و در نتيجه با نتايج منفى عملكرد مرتبط هستند (جانستون،

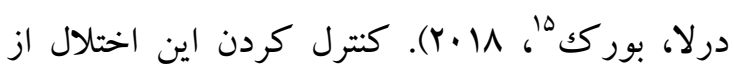
اهميت ويزهاى برخوردار است، جراكه اين رفتارها

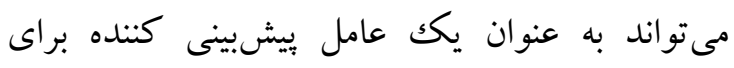

\footnotetext{
${ }^{10}$ - Yousefi et al

11- Mikolajewski, Taylor, Iacono

${ }^{12}$ - Schoorl, Van Rijn, de Wied, Van Goozen, Swaab

13 - Hamilton SS, Armando

14- Servatyari et al

15 - Johnston, Derella, Burke
}

\section{مقلدمه}

اختلال نافرمانى مقابلهاى' يكك مشكل شايع كلينيكال در كودكان و بزرگكسالان محسوب شده و به عنوان يكك الكوى خلق عصبى - تحريككيذير، رفتار مجادله - مقابلهاى تلافىجويانه كه حداقل شش ماه تداوم داشته باشد، تعريف شده است (باردينى، فريك و و

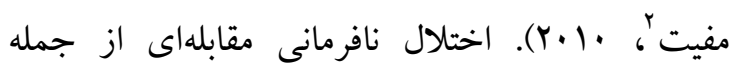

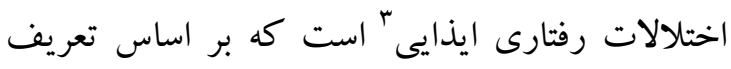
جديد DSM5، الكوى بايدار منفى كارى، نافرمانى، لجبازى، خصومت و سركشى در برابر مراجع قدرت است كه حداقل 9 ماه طول كشيده باشد (موسسه

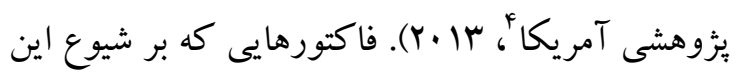

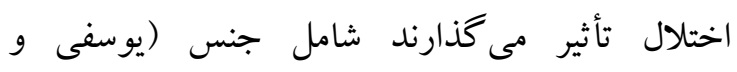

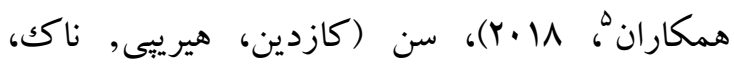
كسلر

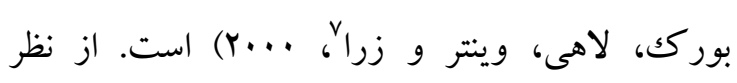
وضعيت اقتصادى اجتماعى، بيشترين شيوع در بين افرادى بوده كه وضعيت اقتصادى اجتماعى بايينترى

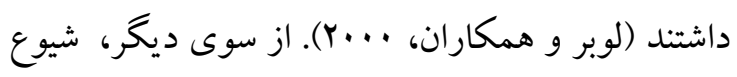
اختلال نافرمانى مقابلهاى با جنس رابطه داشته به نحوى كه در كودكى در يسران شايعتر از دختران است

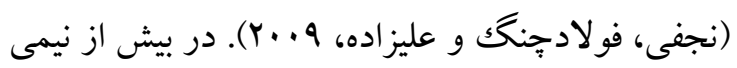
از كودكان، اين اختلال همراهى دارد با اختلالات روانيزشكى ديخر كه از شايعترين اختلال همراه با آن، مىتوان به اختلال كم توجهى بيش فعالى ماشاره كرد

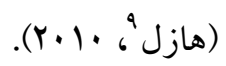

\footnotetext{
1- Oppositional Defiant Disorder (ODD)

2 - Pardini, Frick, Moffitt

3 - Disruptive Behavior

4. Association America

5. Yousefi et al

${ }^{6}$ - Kazdin, Hiripi, Nock, Kessler

7- Loeber, Burke, Lahey, Winters, Zera

8 - Attention deficit hyperactivity disorder (ADHD)

- Hazell
} 
اختلالات روانيزشكى، به جزء اختلال نافرمانى بودند. جامعه آمارى از طريق روش نمونه گيرى تصادفى طبقه

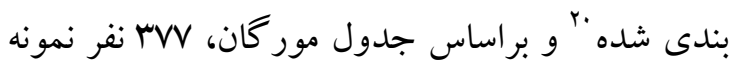

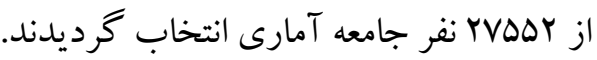

ابزار

ابزار مطالعه حاضر شامل يُرسنامه علائم مرضى إِى

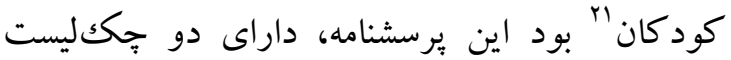
والد و معلم است .جككليست والد: جِك ليست والد، Q Vو سؤال داشت و VV اختلال را مىسنجيد.

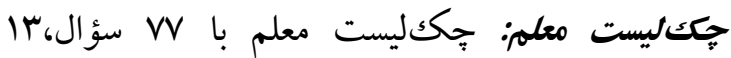
اختلال را موردسنجش قرار مىداد، كه r I سؤال آن مربوط به ارزيابى اختلال نافرمانى كود كان است. نسخه ايرانى :يرسشنامه را محمد اسماعيل و على يور (INM)

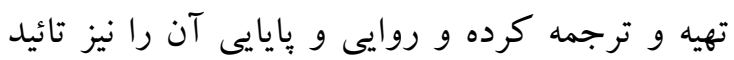

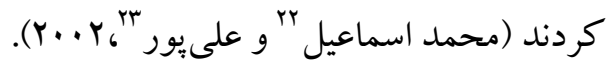

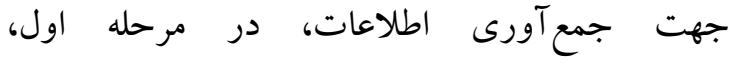

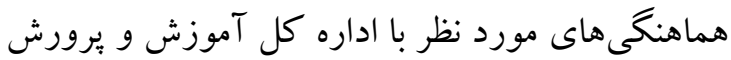
استان انجام شد؛ ازآنجاكه مدارس آموزشويرورش مورد شهر سنندج به دو منطقه اول و دوم تقسيمشده است، لذا تعداد مدارس هر منطقه به نسبت كل مدارس محاسبه گرديد و در مرحله بعد مدارس فوق از ميان كل مدارس هر منطقه، به شكل تصادفى تعيين گرديد و تعداد نمونهها به نسبت تعداد دانش آموز هر مدرسه و بر اساس جنسيت آنها، مشخص گرديد. سبس نمونهها از طريق روش نمونه گيرى تصادفى ساده در هر مدرسه

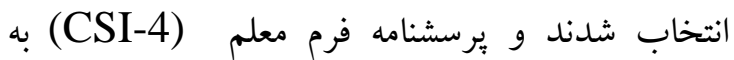
معلمين مربوطه داده شد كه در مورد نمونههاى انتخابى ير كنند. در اين خصوص قبل از اجرا معلمين توجيه شدند كه بر اساس برسشنامه نظر خويش را در مورد

${ }^{20}$ - Stratified random sampling Method

${ }^{21}$ - Child Symptom Inventory

22. Mohamadesmaiel

${ }^{23}$ - Alipour
بزهكارى، سوءمصرف مواد، نافرمانى و افت تحصيلى

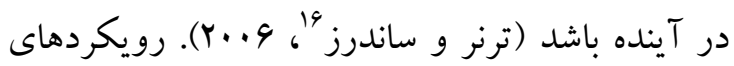
درمان اختلال نافرمانى مقابلهاى شامل آموزش مديريت والدين، رواندرمانى فردى، خ خانوادهدرمانى، درمان شناختى رفتارى و آموزش مهارتهاى اجتماعى است رونى

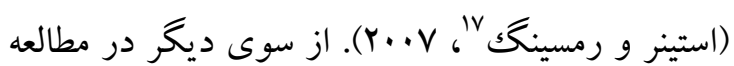
كادو و همكاران، نشان دادند كه دارو درمانى در كنار آموزش والدين بر كاهش نشانهاى اختلال نافرمانى

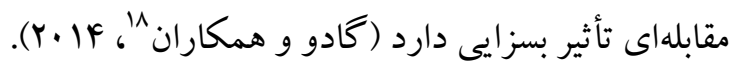
بنابراين به نظر مىرسد كه از رايجترين و مفيدترين روشهاى درمانى اين اختلال، فرزند برورى مناسب و مداخلات خانوادكى با استفاده از آموزش مستقيم والدين و آموزش نشانها و مهارتهاى والدين در كنترل كودكان است. در مطالعهى ثروت يارى و و ورن همكاران مشاهده شد كه در خانو ادههاى با سبك فرز درند يرورى مقتدرانه، بروز مشكلات رفتارى در كودكان آنها اعم از خشونت، كمتر ديده مىشود (ثروت يارى

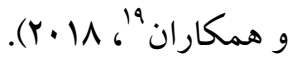

با توجه به اهميت اختلال نافرمانى مقابلهاى در شكل گيرى شخصيت و رفتار كودكان و هم: هنين تأثيرات آن بر سلامت كودكان و خانوادههاى آنها، هدف از اين يزٔوهش، تعيين شيوع اختلال نافرمانى مقابلهاى و عوامل مرتبط با آن در بين دانش آموزان

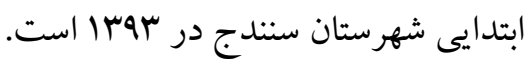

مطالعه حاضر، يك مطالعه مقطعى است. جامعه موردمطالعه شامل دانش آموزان مقطع ابتدايى ساكن در

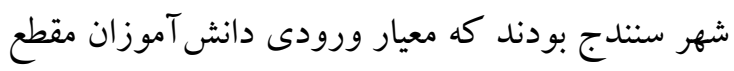
ابتدائى و معيار خروجى آن دانش آموزانى كه داراى

\footnotetext{
16. Turner KM, Sanders MR

${ }^{17}$ - Steiner, Remsing

18 - Gadow et al

19- Servatyari et al
} 


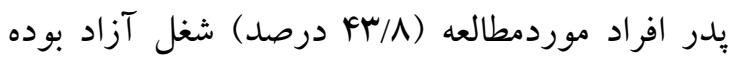

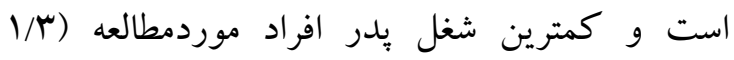
درصد) بيكار بود. بيشترين شغل مادر افراد موردمطالعه

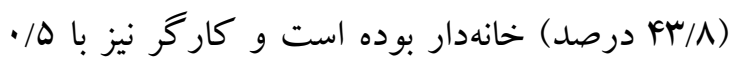
درصد كمترين شغل مادر افراد موردمطالعه را تشكيل مىدادند. بيشترين تحصيلات يدر افراد موردمطالعه (F) درصد) ليسانس و بالاتر بوده است و بيشترين تحصيلات مادر افراد موردمطالعه (ها درصد) ليسانس

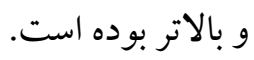
بر اساس نتايج به دست آمده، ميانگين نمره اختلال نفرمانى در بين بِران و دختران باهم تفاوت معنادارى

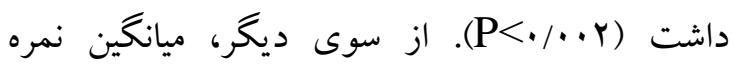
اختلال نافرمانى بر اساس سابقه جدايى والدين از لحاظ

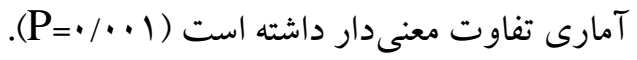

دانشآموز خود بنويسند. درنهايت، اطلاعات وارد نرمافزار آمارى SPSS-18 كرديد. اطلاعات حاصل از تكميل برسشنامهها جمع آورى و وارد نرمافزار

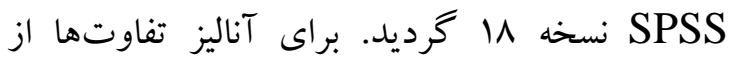
آزمون تى تست مستقل و ضريب همبستخى بيرسون

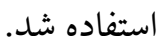

\section{يافته ها} نتايج مطالعه نشان داد كه از ميان MVV دانش آموز مورد

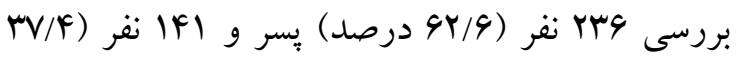

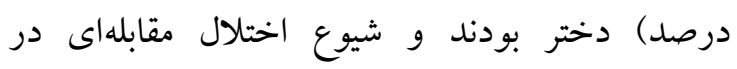

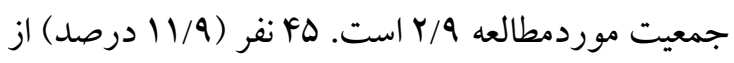
افراد موردمطالعه سابقه طلاق والدين در آنها وجود دارد، در Vا نفر (ه/D درصد) از افراد موردمطالعه سابقه جدايى والدين در آنها وجود داشت، بيشترين شغل

جدول ا تعيين تفاوت ميانكين نمره اختلال نافرمانى با توجه به سابقه جدايى والدين

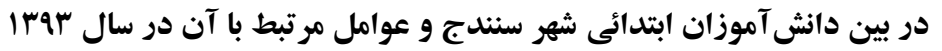

\begin{tabular}{|c|c|c|c|c|c|c|c|}
\hline سعنادارى سطح & t toاره & آزادى & $\begin{array}{c}\text { انحر اف معيار } \\
\pm\end{array}$ & ميانتين & فراوانى & & \\
\hline \multirow[t]{2}{*}{$\cdot / \cdot \cdot 1$} & \multirow[t]{2}{*}{$-r / T V$} & \multirow[t]{2}{*}{ rVD } & $\Delta / I T$ & $V / I f$ & r4. & ندارد & \multirow[t]{2}{*}{ سابقه جدايیى والدين } \\
\hline & & & F/GY & $11 / 41$ & IV & دارد & \\
\hline
\end{tabular}

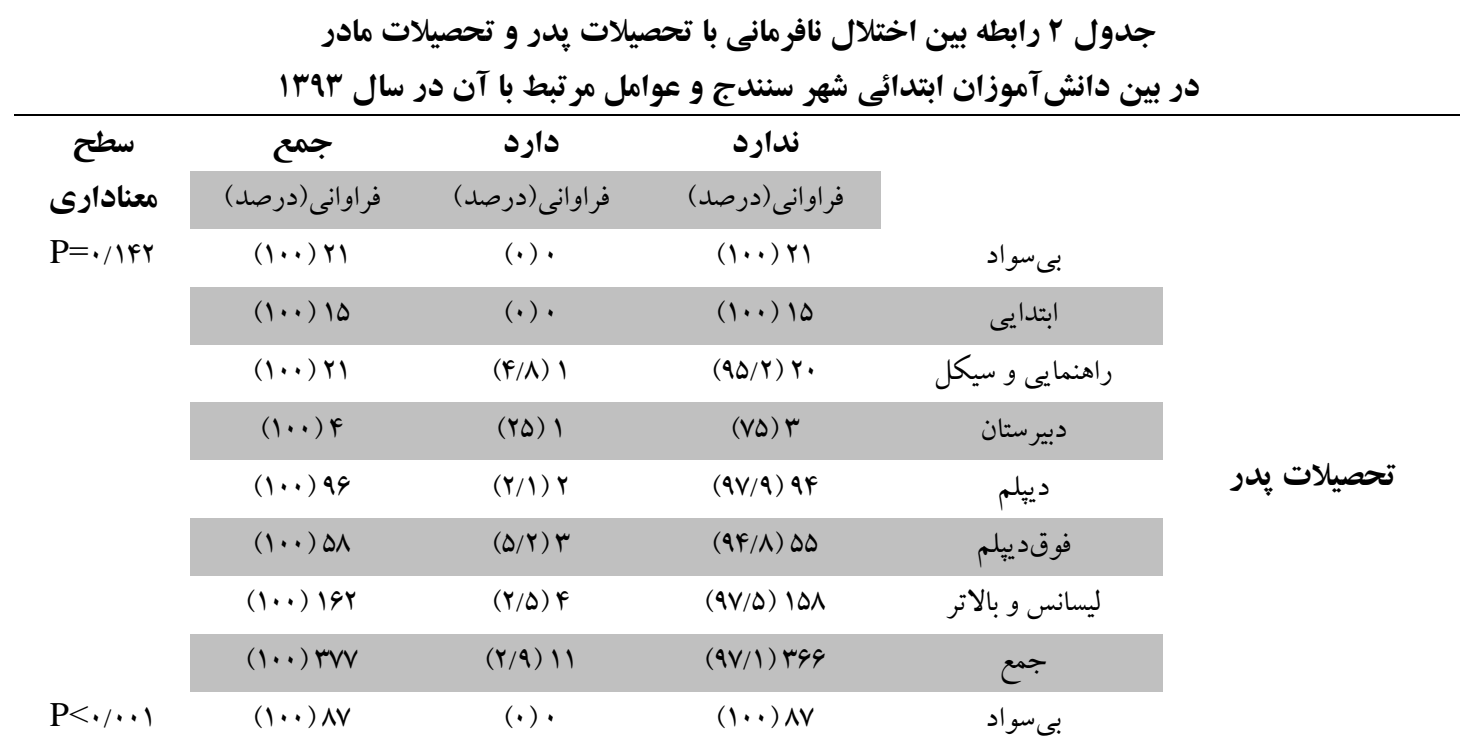




\begin{tabular}{|c|c|c|c|c|}
\hline$(I \ldots) Y I$ & $(\boldsymbol{F} / \Lambda) 1$ & $(9 \Delta / r) r$. & ابتدايى & \\
\hline$(1 \ldots) r$. & (ه) 1 & $(9 \Delta) 19$ & راهنمايى و سيكل & \\
\hline$(1 \ldots) F$ & $(\Delta \cdot) r$ & $(\Delta \cdot) r$ & دبيرستان & تحصيلات مادر \\
\hline$(1 \cdots) \mathrm{VI}$ & $(1 / F) 1$ & $(q \Lambda / \Delta) \vee$. & دييلم & \\
\hline$(1 \ldots) \mathrm{Fr}$ & $(F / \Delta) r$ & $(9 \Delta / r) F$. & فوقدييلم & \\
\hline (1...) (rr & $(r) F$ & $(q V) \mid r \wedge$ & ليسانس و بالاتر & \\
\hline$(1 .) r V V$. & $(Y / 9) 11$ & $(9 V / 1) r 99$ & جمع & \\
\hline
\end{tabular}

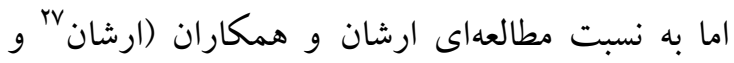
همكاران، F ..... كه در تر كيه انجامشده بود و در آن مطالعه شيوع 11/ه درصد ثبت شده بود و مطالعه

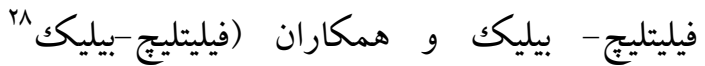

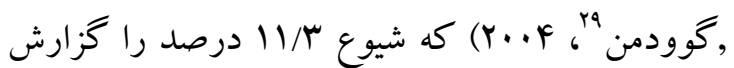
كرده بودند و همجِنين مطالعه ميشرا و همكاران كه بر

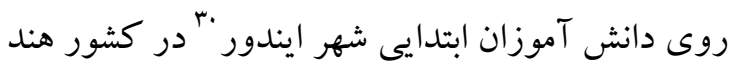

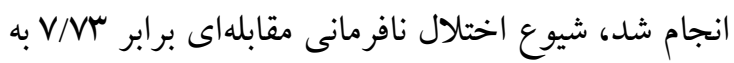

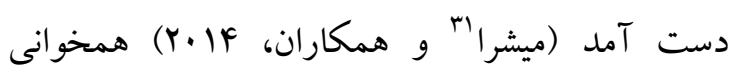
ندارد؛ شايد دليل مغايرت را بتوان به تعداد نمونهها، ابزار كردآورى دادهها و همجِنين تفاوتهاى فردى و و قومى در بين مطالعهى حاضر با مطالعات اشاره شده نسبت داد، به طورى كه تعداد نمونههاى مطالعه حاضر rVV IFYD شيوع اختلال نافرمانى مقابلهاى در بين كودكان ييشدبستانى در مطالعه نيمكزيك و همكاران،

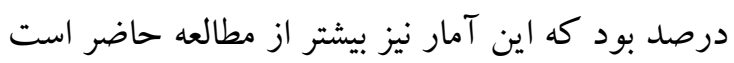

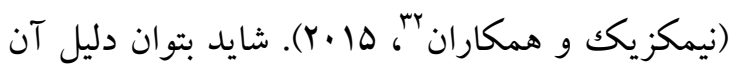
را تفاوت در ابزار گرداورى اطلاعات، سال انجام مطالعه و تفاوتهاى فرهنگى جوامع مذكور در نظر

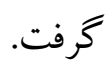

\footnotetext{
${ }^{27}$ - Erșan

${ }^{28}$ - Fleitlich-Bilyk

${ }^{29}$ - Goodman

${ }^{30}$ - Indore

31- Mishra

${ }^{32}$ - Niemczyk et al
}

جدول فوق نشان مىدهد كه بين اختلال نافرمانى با تحصيلات بدر رابطه معنىدار آمارى وجود ندارد (P=•//FY) تحصيلات مادر رابطه معنىدار آمارى وجود دارد $(\mathrm{P}<\bullet / \cdot \cdot)$

و در انتها، بر اساس ضريب همبستخى بيرسون، بين

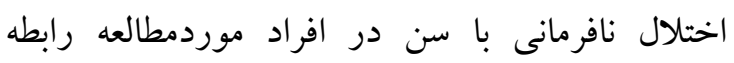
معنى نتايج مطالعه حاضر نشان داد كه شيوع اختلال نافرمانى

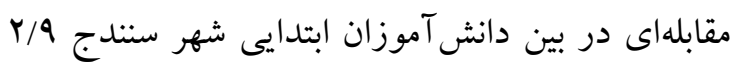
درصد است اين نتايج همسو با نتايج مطالعه نجفى و همكاران (نجفى و همكاران اين اختلال را در شيراز در سال

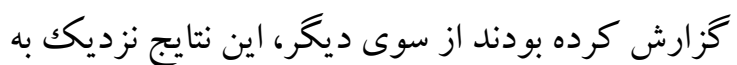

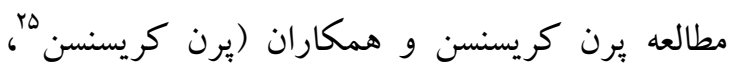

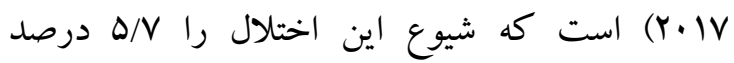
كزارش كرده بودند؛ همجينين در مطالعهى جانستون و همكاران كه بر روى افراد MF-1 اين نتيجه رسيدند كه شيوع اختلال نافرمانى مقابلهاى در افراد موردمطالعه، هץ/r درصد بود كه مطابق با نتايج

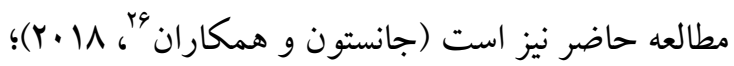

\footnotetext{
24- Najafi M et al

25 - Prehn-Kristensen et al

26- Johnston et al
} 
اثبات رسيد كه اين نتايج برخلاف مطالعه حاضر است، شايد دليل اين مسئله را بتوان به سال انجام مطالعه، ابزار و تفاوت قوميتى و فرهنگ四 بين دو جامعه مورد نظر نسبت داد. در هر صورت تحصيلات مادر خانواده، نقش بسيار مهمى در بروز اختلالت رفتارى كود كان در مرور مطالعات مختلف داشته است. از آنجا كه اختلال نافرمانى مقابلهاى، سبب برون خشونت در كود كان مى شود، لذا با توجه به مطالعه ثروت يارى و همكاران، كودك آزارى در كودكان سبب بروز يرخاشكرى در آنها شده كه خود به ريسك فاكتور براى بروز اختلال نافرمانى مقابلهاى است (ثروت يارى و همكاران، M • (Y). در مطالعه حاضر، جنس و سن نقش مهمى در ميزان اين اختلال داشت، بهنحوى كه اختلال نافرمانى مقابلهاى بهتدريج در سالهاى بيشدبستانى ييشرفت مى كند و

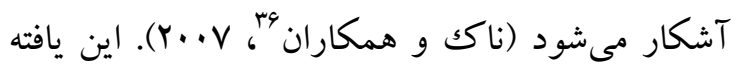
مطابق با مطالعات مختلف است كه در آنها اختلال نافرمانى مقابلهاى با افزايش سن كاهش مي ميابد بهنحوى كه دريكى از مطالعات (نيمكز يكك و همكاران، ها.Y.T)، شيوع اختلال نافرمانى مقابلهاى در دانش آموزان بيشدبستانى س/. 1 و در مطالعهاى ديخر

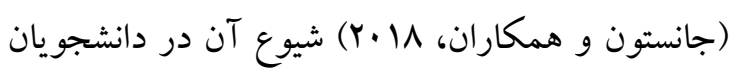
qس/ץ بود، اين نتايج به اين معنا است كه اختلال نافرمانى مقابلهاى تنها مربوط به كودكى نبوده و در سنين جوانى نيز خود را نشان خو اهد داد.

\section{نتيجه كيرى}

شيوع اختلال نافرمانى مقابلهاى در بين دانش آموزان ابتدايى شهر سنندج Y/9 درصد است و عواملى مانند جنسيت، سابقه جدايى والدين و تحصيلات مادر بر آن تأثير دارند؛ بنابراين با توجه به اهميت دوران كودكى ولى

${ }^{36}$ - Nock et al
از ديخر نتايج مطالعه حاضر اين بود كه اختلال نافرمانى مقابلهاى با سابقه جدايى والدين در افراد موردمطالعه

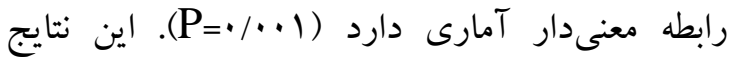
همسو با نتايج مطالعه ارشان و همكاران (ارشان و واري همكاران" بان) بود كه در آن مطالعه خانوادههايى كه جدايى در بين همسران اتفاق افتاده بود شيوع اختلالات به نسبت خانوادههايى كه زندگى آرامى داشتند بيشتر كزارش شد. اين يافته مى تواند قابل دركك و تفسير باشد زيرا كه جدايى والدين سبب بروز استرس شديد و در نتيجه سبب بروز اختلال ساز گارى در طى زند كودكك شده و كودكان با توجه به تجربه محدود توانايى مقابله صحيح با اين استرس شديد را ندارند و وند بهد سبب بروز اختلالت رفتارى در آنها مىشود. در مطالعه حاضر، بين اختلال نافرمانى مقابلهاى با تحصيلات يدر رابطه معنىدار آمارى وجود ندارد

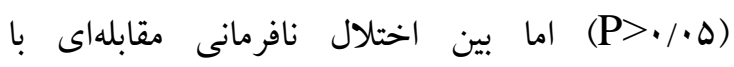
تحصيلات مادر رابطه معنىدار آمارى ديده شد (P=•/・1) تربيت و ارتباط مناسبى كه با فرزند برقرار مى كند بيشتر تأكيد مى كند كه اين يافته با نتايج شنكك و وني

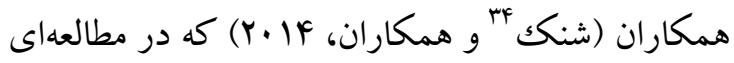
قرار گرفتن در معرض خشونت بين فردى و ياسخ به درمان طولانىمدت در بيماران مبتلا به اختلال نافرمانى مقابلهاى را بررسى كرده بودند و در آن مطالعه نيز تحصيلات والدين رابطه معنىدارى با اين اختلال داشت

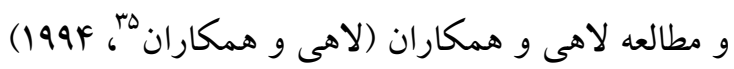
كه از نقش مؤثر تحصيلات والدين نامبرده است همخوانى و مطابقت دارد. از سوى ديخر در مطالعه

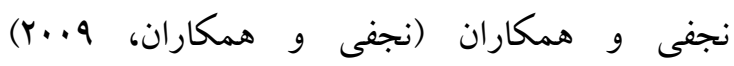
تحصيلات يدر در بروز اختلال نافرمانى مقابلهاى به

\footnotetext{
${ }^{3}$ - Erşan et al

34 - Shenk et al

35. Lahey et al
} 
Hamilton SS, \& Armando J. (2008). Oppositional defiant disorder. Am Fam Physician, 78(7), 861-866.

Hazell P. (2010). Review of attentiondeficithyperactivity disorder comorbid with oppositional defiant disorder. Australas Psychiatry, 18(6), 556-559. doi: 10.3109/10398562.2010.498049

Johnston OG, Derella OJ, \& Burke JD. (2018). Identification of Oppositional Defiant Disorder in Young Adult College Students. Journal of Psychopathology and Behavioral Assessment, 40(4), 563-572.

Lahey BB, Applegate B, Barkley RA, Garfinkel B, McBumett K, Kerdyk L, . . Newcorn J. (1994). DSM-IV field trials for oppositional defiant disorder and conduct disorder in children and adolescents. American joumal of psychiatry, 151(8), 1163-1171.

Loeber R, Burke JD, Lahey BB, Winters A, \& Zera M. (2000). Oppositional defiant and conduct disorder: a review of the past 10 years, part I. Journal of the American Academy of Child \& Adolescent Psychiatry, 39(12), 14681484.

Mikolajewski AJ, Taylor J, \& Iacono WG. (2017). Oppositional defiant disorder dimensions: genetic influences and risk for later psychopathology. Joumal of Child Psychology and Psychiatry, 58(6), 702-710.

Mishra A, Garg S, \& Desai SN. (2014). Prevalence of oppositional defiant disorder and conduct disorder in primary school children. Joumal of Indian Academy of Forensic Medicine, 36(3), 246-250.

Mohamadesmaiel E, \& Alipour A. (2002). A preliminary study on the reliability, validity and cut off points of the disorders of Children Symptom Inventory-4 (CSI-4). Journal of Exceptional Children, 2(3), 239254.

Najafi M, Foladchang M, Alizadeh H, \& MA, M. (2009). Prevalence of attention deficit hyperactivity disorder, conduct disorder and oppositional defiant disorder. Research on Exceptional Children, 9(3), 239-254.

Niemczyk J, Equit M, Braun-Bither K, Klein AM, \& von Gontard A. (2015). Prevalence of incontinence, attention deficithyperactivity disorder and oppositional defiant disorder in

$$
\begin{aligned}
& \text { در شكل گيرى رفتار و شخصيت يكك فرد و همجِنين } \\
& \text { اهميت بسيار زياد نافرمانى مقابلهاى، لذا برنامهريزى در } \\
& \text { جهت شناسايى و كاهش خطرات ناشى از آن و عوامل }
\end{aligned}
$$

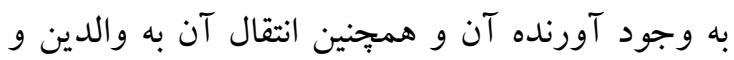

$$
\begin{aligned}
& \text { كسانى كه بهطور مستقيم با كودكان در ارتباط هستند، }
\end{aligned}
$$

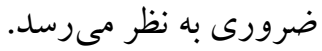

$$
\begin{aligned}
& \text { سياسگزارى } \\
& \text { نويسندكان مقاله مراتب تشكر و قدردانى خود را از } \\
& \text { شوراى يُزوهشى دانشكده يزشكى دانشگاه علوم } \\
& \text { يزشكى كردستان به خاطر حمايت از طرح زير اعلام } \\
& \text { مىدارد. اين مقاله استخراج يافته از باياننامه دورهى } \\
& \text { دكترى عمومى دانشجويان آقاى دكتر محمدشاه ويسى } \\
& \text { و سر كار خانم دكتر سارا شاه ويسى با همين عنوان كه } \\
& \text { در تاريخ } 19 \text { آبان ץوسا تصويب شده بود، است. }
\end{aligned}
$$

\section{References}

Association AP. (2013). Diagnostic and statistical manual of mental disorders (DSM-5®): American Psychiatric Pub.

Erşan EE, Doğan O, Doğan S, \& Sümer H. (2004). The distribution of symptoms of attentiondeficithyperactivity disorder and oppositional defiant disorder in school age children in Turkey. European child \& adolescent psychiatry, 13(6), 354-361.

Fleitlich-Bilyk B, \& Goodman R. (2004). Prevalence of child and adolescent psychiatric disorders in southeast Brazil. Joumal of the American Academy of Child \& Adolescent Psychiatry, 43(6), 727-734.

Gadow KD, Amold LE, Molina BS, Findling RL, Bukstein OG, Brown NV, ... Aman MG2. (2014). Risperidone added to parent training and stimulant medication: effects on attention-deficithyperactivity disorder, oppositional defiant disorder, conduct disorder, and peer aggression. J Am Acad Child Adolesc Psychiatry, 53(9), 948-959. doi: 10.1016/j.jaac.2014.05.008 
preschool children. European child \& adolescent psychiatry, 24(7), 837-843.

Nock MK, Kazdin AE, Hiripi E, \& Kessler RC. (2007). Lifetime prevalence, correlates, and persistence of oppositional defiant disorder. results from the National Comorbidity Survey Replication. Joumal of Child Psychology and Psychiatry, 48(7), 703-713.

Pardini DA, Frick PJ, \& Moffitt TE. (2010). Building an evidence base for DSM-5 conceptualizations of oppositional defiant disorder and conduct disorder. Introduction to the special section. Joumal of abnormal psychology, 119(4), 683.

Prehn-Kristensen A, Molzow I, Förster A, Siebenhühner N, Gesch M, Wiesner CD, \& Baving L. (2017). Memory consolidation of socially relevant stimuli during sleep in healthy children and children with attentiondeficithyperactivity disorder and oppositional defiant disorder: What you can see in their eyes. Biological psychology, 123, 196-204.

Schoorl J, Van Rijn S, de Wied M, Van Goozen SH, \& Swaab H. (2017). Neurobiological stress responses predict aggression in boys with oppositional defiant disorder/conduct disorder: a 1-year follow-up intervention study. European child \& adolescent psychiatry, 26(7), 805-813.

Servatyari K, Mardani N, Servatyari B, \& Yazdanpanah H. (2019). The study of factors affecting concentration in classroom among high school students in Divandarreh City, Iran, in 2018. Chronic Diseases Journal, 7(3), 153-159. doi: http:// dx.doi.org/10.22122/cdj.v0i0.425

Servatyari K, Valizadeh Ardalan P, Yazdnpanah S, Mardani N, Yazdan Panah H. (2019). Frequency of psychological disorders symptoms and their effects on high school students in Divandareh city in 2018.
Shenakht Joumal of Psychology and Psychiatry, 6(3), 71-82.

Servatyari K, Yousefi F, Kashefi H, Bahmani MP, Parvareh M, \& Servatyari S. (2018). The relationship between parenting styles with the aggression of their children in sanandaj primary students. Intemational Journal of Biomedicine and Public Health, 1(3), 141147. doi: 10.22631/ijbmph.2018.117376.1018

Servatyari K, Yazdanpanah H, Rasouli M, Yousefi F. (2018). Surveying of relationship between child abuse and aggression in primary school students in Sanandaj City-Iran. Intemational Joumal of Biomedicine and Public Health, 1(4), 162-168. doi: 10.22631/ijbmph.2018.120807.1030

Shenk CE, Dom LD, Kolko DJ, Rausch JR, \& Insana SP. (2014). Prior Exposure to Interpersonal Violence and Long- Term Treatment Response for Boys With a Disuptive Behavior Disorder. Journal of traumatic stress, 27(5), 585-592.

Steiner H, \& Remsing L. (2007). Practice parameter for the assessment and treatment of children and adolescents with oppositional defiant disorder. Joumal of the American Academy of Child \& Adolescent Psychiatry, 46(1), 126-141.

Turner KM, \& Sanders MR. (2006). Help when it's needed first: a controlled evaluation of brief, preventive behavioral family intervention in a primary care setting. Behav Ther, 37(2), 131-142. doi: 10.1016/j.beth.2005.05.004

Yousefi F, Shahvesi S, Shahvisi M, \& Servatyari K. (2017). The Relationship between Gender Difference and the History of Psychiatric Disorders in the Family with Oppositional defiant disorder among Primary School Students in Sanandaj in 2014. Shenakht J Psychol Psychiat, 4(3), 58-64. 